\title{
Influência da camada do revestimento de argamassa na penetração de cloretos em estruturas de concreto
}

\author{
Influence of the mortar rendering layer on chloride \\ penetration into concrete structures
}

\section{Raphaele Meireles de Castro Malheiro Gibson Rocha Meira Munique Silva de Lima}

\section{Resumo}

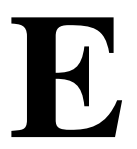

ste trabalho estudou a influência da camada de revestimento em argamassa na penetração de cloretos no concreto. Para tanto, foram moldados corpos de prova de concreto nas dimensões $8 \mathrm{~cm}$ x $8 \mathrm{~cm}$ x 8 $\mathrm{cm}$ e relação água/cimento de 0,55 , sobre os quais foram aplicados três tipos de argamassa de revestimento, após uma fina camada de chapisco. Vencidos os períodos de cura de 28 dias para o concreto e a argamassa de revestimento, cinco das seis faces dos CPs foram isoladas com resina epóxi para simular um fluxo unidirecional. Esses CPs foram submetidos ao ensaio de imersão e secagem por 49 dias e, após isso, foram retiradas e analisadas amostras para a obtenção dos perfis de cloretos. Os resultados indicam que as argamassas de revestimento influenciam no transporte de cloretos no concreto e que essa influência é mais pronunciada para as argamassas menos porosas e mais ricas em cimento. Também se observou um acúmulo de cloretos na região próxima à interface argamassaconcreto, o qual é explicado pelas diferenças na capacidade de transporte entre a argamassa e o concreto. Apesar de as argamassas serem mais porosas que o concreto, elas podem representar uma proteção adicional em relação ao retardamento na penetração de cloretos no concreto.

Palavras-chave: Argamassa. Concreto. Corrosão. Durabilidade. Transporte de cloretos.

Raphaele Meireles de Castro Malheiro Universidade do Minho Guimarães - Portugal

Gibson Rocha Meira Instituto Federal de Educação, Ciência e Tecnologia da Paraíba João Pessoa - PB - Brasil

Munique Silva de Lima Instituto Federal de Educação, Ciência e Tecnologia da Paraíba João Pessoa - PB - Brasil

Recebido em 13/02/13 Aceito em 13/12/13

\section{Abstract}

This study investigated the influence of the rendering mortar layer on chloride penetration in concrete. Cubic concrete specimens were cast measuring $8 \mathrm{~cm} \times 8$ $\mathrm{cm} \times 8 \mathrm{~cm}$ and $a$ water to cement ratio of 0.55. Three different mortar mixtures were used to cover one concrete face, after a thin layer of spatter dash treatment. Reference concrete specimens were also cast. After curing periods of 28 days for concrete and mortar rendering, five out of the six faces of the specimens were coated with epoxy resin to simulate unidirectional flow. The specimens were then subjected to wetting and drying cycles for 49 days and, afterwards, samples were extracted and analysed to obtain chloride profiles. The results show that mortar renderings influence chloride transport into concrete and this is more accentuated for less porous mortars and with higher cement content. There is also chloride accumulation close to the mortar-concrete interface region, which is explained by the differences in the chloride transport ability between mortar and concrete. Although mortars are more porous than concrete, they can represent an additional protection against chloride penetration into concrete.

Keywords: Mortar. Concrete. Corrosion. Durability. Chloride transport. 


\section{Introdução}

A deterioração precoce de estruturas de concreto armado em zonas costeiras tem-se apresentado como um problema importante nas últimas décadas. A ação dos íons cloreto, como agente desencadeador da corrosão de armaduras, é, certamente, uma das mais importantes causas de degradação de estruturas de concreto nesse ambiente (AITCIN, 2000). Esses íons penetram no interior do concreto, principalmente através dos mecanismos de absorção capilar e difusão (KRÖPP et al., 1995; NILSSON; TANG, 1996) e, ao atingirem a superfície das armaduras, em quantidade suficiente, dão início ao processo de corrosão (GLASS; BUENFELD, 1997; CASTRO; RINCÓN; PAZINI, 2001). Esse transporte ocorre a partir do contato da superfície do concreto ou de camadas a ela superpostas com a água do mar ou, em boa parte dos casos, através de seu contato com o aerosol marinho (MEIRA et al., 2007a, 2007b; LINDVALL, 2007)

Estudos sobre a influência das características dos materiais no transporte de cloretos no concreto mostram o papel de aspectos como a estrutura porosa dos materiais (TUUTTI, 1982; JAEGERMANN, 1990; MANGAT; MOLLOY, 1994), a presença de fissuras (MANGAT; GURUSAMY, 1987; BAKKER, 1988) e a capacidade de fixação de cloretos na matriz empregada (BYFORS, 1990; RASHEEDUZZAFAR; HUSSAIN; ALSAADOUN, 1990) na aceleração ou retardo no transporte de cloretos no concreto. Avaliações sobre a influência das características ambientais representam outra parcela de estudos, abordando aspectos como temperatura (PAGE; SHORT; EL TARRAS, 1981; AL-KHAJA, 1997), carbonatação do concreto (BYFORS, 1990; JONES; MACCARTHY; DHIR, 1994) e grau de saturação dos poros do concreto (NIELSEN; GEIKER, 2003; GUIMARÃES; HELENE, 2005).
Esses trabalhos consideraram os materiais, concreto ou argamassa, de forma isolada, sem a presença conjunta de ambos, caracterizando um sistema em camadas com materiais distintos. No entanto, essa é a situação de boa parte dos edifícos construídos em zona de influência marinha, onde as estruturas de concreto se encontram revestidas e a camada de argamassa representa uma barreira inicial a ser transposta antes de os íons cloreto chegarem ao concreto.

Acerca desse tema, Crank (1975) realizou desenvolvimento matemático sobre o transporte de massa em sistemas duplos considerando o transporte por difusão. Tomando como base o efeito pele, Andrade, Diez e Alonso (1997) propuseram as Equações 1-3 como solução para representar o transporte de cloretos por difusão em materiais com características de transporte diferentes entre a superfície e o interior. Nessa estrutura, $C_{l}$ corresponde à concentração de cloretos na camada mais externa, $C_{2}$ é a concentração de cloretos na camada interior, $D_{l}$ é o coeficiente de difusão da camada mais externa, $D_{2}$ é o coeficiente de difusão da camada interior, $C s$ é a concentração superficial de cloretos, erfc é a função erro complementar, $e$ representa a espessura da camada externa (pele), $R$ corresponde à resistência entre as duas camadas, $x$ corresponde à profundidade em estudo e $t$ representa o tempo de exposição em estudo (Figura 1).

$$
\begin{aligned}
& C_{1}=C_{s} \sum_{n=0}^{\infty} \alpha^{n}\left(\operatorname{erfc}\left[\frac{2 n e+x}{2 \sqrt{D_{1} t}}\right]-\alpha e r f c\left[\frac{(2 n+2) e-x}{2 \sqrt{D_{1} t}}\right]\right) \\
& C_{2}=\frac{2 k C_{s} R}{k+1} \sum_{n=0}^{\infty} \alpha^{n} \operatorname{erfc}\left[\frac{(2 n+1) e+k(x-e)}{2 \sqrt{D_{1} t}}\right] \\
& k=\sqrt{\frac{D_{1}}{D_{2}}} ; \quad \alpha=1-k / 1+k ; \quad C_{1}=R C_{2}
\end{aligned}
$$

Eq. 3

Figura 1 - Representação esquemática de um sistema duplo em camadas com distintas características de transporte

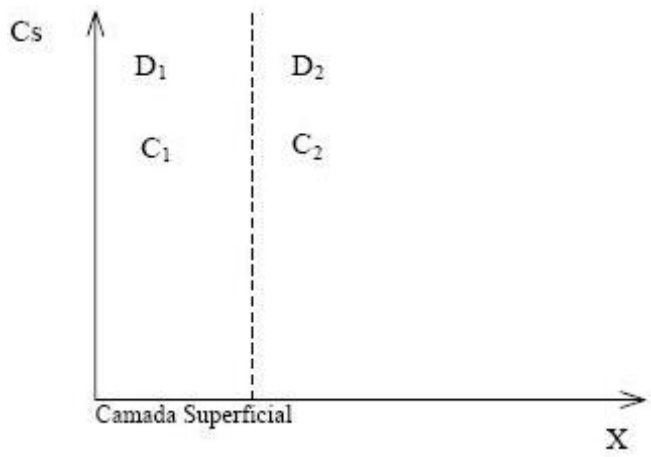

42 Malheiro, R. M. de C.; Meira, G. R.; Lima, M. S. de. 
Embora essa abordagem tenha algumas limitações, como, por exemplo, a não consideração da dependência do coeficiente de difusão em relação ao tempo ou a não linearidade da capacidade de fixação de cloretos na matriz cimentícia, ela provê informações bastante úteis para o caso de sistemas duplos, sem a necessidade da entrada de múltiplos parâmetros. Nesse caso, trata-se de uma dificuldade para os modelos mais sofisticados (MARTIN-PÉREZ, 1999; MEIJRES, 2003).

Estudos sobre o transporte em sistemas duplos encontram-se, em sua maioria, no campo das simulações, havendo carência de estudos experimentais. Uma contribuição no campo experimental foi realizada por Kreijger (1984), que identificou a formação de uma camada superficial mais porosa, com características de transporte diferenciadas em relação ao interior do concreto, caracterizando o efeito pele (ANDRADE; ALONSO, 1997; ANDRADE; DIEZ; ALONSO, 1997). No entanto, apesar dos vários estudos realizados em concreto e em argamassa separadamente, pouco se investigou, no campo experimental, sobre o comportamento conjunto desses materiais em relação ao transporte de cloretos.

Nesse contexto, o presente trabalho desenvolve um estudo experimental sobre a influência do transporte de cloretos em argamassas de revestimento na penetração de cloretos em estruturas de concreto revestidas, através de sistemas duplos, simulando as condições de aplicação dos materiais em campo.

\section{Materiais e programa experimental}

\section{Materiais empregados}

Os agregados empregados na pesquisa foram areia natural quartzosa, com módulo de finura 2,2 e diâmetro máximo de $4,8 \mathrm{~mm}$, e brita granítica, com diâmetro máximo de 9,5 mm, cujas curvas de composição granulométrica são apresentadas na Figura 2. A água utilizada foi água potável proveniente da rede pública, com teor de cloretos da ordem de $1 \mathrm{mg} / \mathrm{l}$, valor este obtido a partir de análises químicas com a técnica de titulação potenciométrica, seguindo procedimento semelhante ao descrito na ASTM C114 (AMERICAN..., 1992). O cimento empregado foi um cimento Portland CPV, cujas características físico-químicas são apresentadas na Tabela 1. Esse cimento foi escolhido em função de seu baixo nível de adições. A cal selecionada para este trabalho foi uma cal $\mathrm{CH} \mathrm{I}$, de uso corrente na região do estudo, cujas características também são apresentadas na Tabela 1 .

\section{Preparação dos corpos de prova}

Os corpos de prova (CPs) utilizados na pesquisa foram desenvolvidos em duas etapas: moldagem do substrato (concreto) e execução da camada de revestimento, seguindo procedimentos usualmente adotados nos canteiros de obras, conforme se descreve mais detalhadamente nos parágrafos 3,4 e 5 desta seção. Também foram moldados CPs de referência em concreto com o objetivo de promover comparações com os CPs revestidos.

Inicialmente, foram moldados cubos de concreto, nas dimensões $8 \times 8 \times 8 \mathrm{~cm}$, cuja dosagem encontra-se detalhada na Tabela 2. A relação água/cimento empregada foi de 0,55 , retratando condição usualmente empregada na região do estudo. Para caracterizar o concreto, ensaios de abatimento, resistência à compressão, absorção capilar e absorção de água foram realizados. Os ensaios de caracterização no estado endurecido foram realizados aos 28 dias (Tabela 2).

Figura 2 - Curvas granulométricas dos agregados miúdo e graúdo
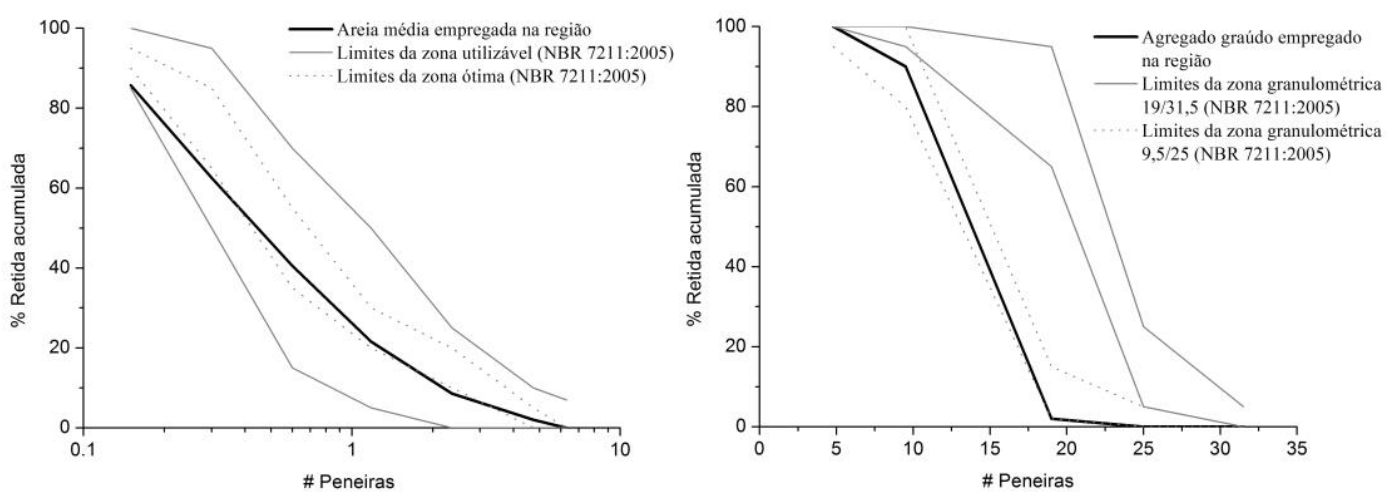
Tabela 1 - Composição química e propriedades físicas do cimento e da cal hidratada

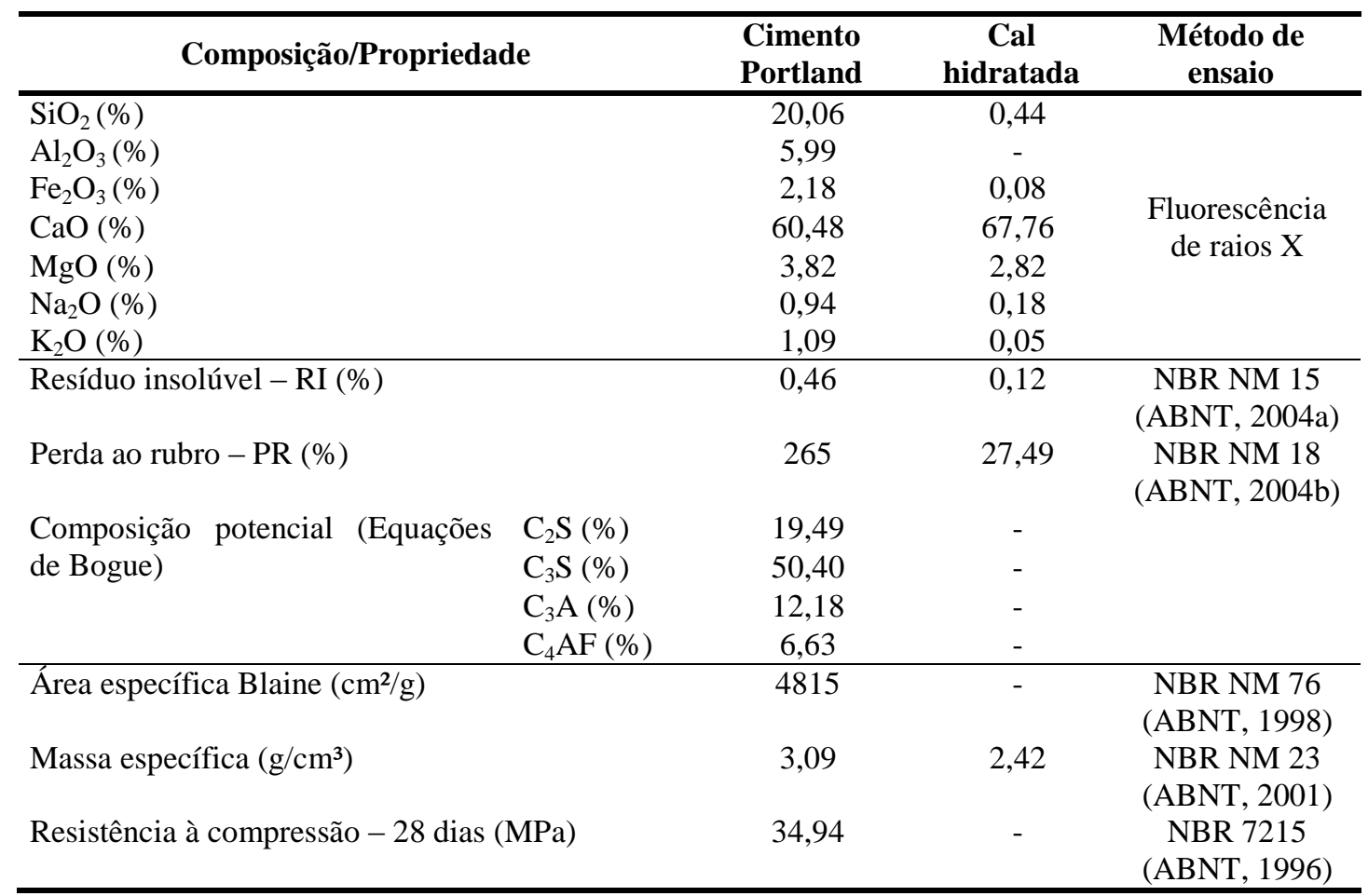

Tabela 2 - Dosagem e propriedades do concreto e das argamassas

\begin{tabular}{|c|c|c|c|c|}
\hline Material & Concreto & $\begin{array}{c}\text { Argamassa } \\
1: 3^{*} \\
\end{array}$ & $\begin{array}{c}\text { Argamassa } \\
1: 1: 6^{*}\end{array}$ & $\begin{array}{c}\text { Argamassa } \\
1: 2: 9^{*} \\
\end{array}$ \\
\hline \multicolumn{5}{|l|}{ Proporções relativas } \\
\hline Cimento $(\mathrm{kg})$ & 1 & 1 & 1 & 1 \\
\hline Cal hidratada (kg) & - & - & 0,30 & 0,59 \\
\hline Areia $(\mathrm{kg})$ & 932,4 & 3,53 & 7,05 & 10,58 \\
\hline Agregado graúdo $(\mathrm{kg})$ & 891,7 & - & - & - \\
\hline Relação água/cimento & 0,55 & 0,6 & 0,83 & 1,11 \\
\hline Cimento $\left(\mathrm{kg} / \mathrm{m}^{3}\right)$ & 370 & 437 & 250 & 173,5 \\
\hline Teor de ar incorporado $(\%)$ & - & 2 & 2 & 4 \\
\hline $\begin{array}{l}\text { Índice de consistência - Slump / } \\
\text { Espalhamento }(\mathrm{mm})\end{array}$ & $70 \pm 10$ & 262 & 264 & 262 \\
\hline $\begin{array}{l}\text { Resistência à compressão }(\mathrm{MPa})- \\
28 \text { dias }\end{array}$ & 30,43 & 23,59 & 11,82 & 5,65 \\
\hline Absorção de água por capilaridade $\left(\mathrm{g} / \mathrm{cm}^{2}\right)$ & 1,43 & - & - & - \\
\hline Absorção após saturação em água (\%) & 4,86 & 8,24 & 10,40 & 11,33 \\
\hline Massa específica da amostra seca $\left(\mathrm{g} / \mathrm{cm}^{3}\right)$ & 2,25 & 2,21 & 2,13 & 2,09 \\
\hline Porosidade total $(\%)$ & 10,95 & 18,19 & 22,13 & 23,72 \\
\hline
\end{tabular}

Nota: * Esta identificação refere-se ao traço da argamassa em volume (cimento: areia ou cimento: cal: areia).

Após desmoldados, os CPs de concreto permaneceram em ambiente de laboratório até 120 dias. Essa condição também se aplicou aos CPs de referência e buscou simular a espera demandada entre a execução do concreto e o revestimento em situações reais de obra. Durante esse período, os corpos de prova permaneceram envolvidos por filme plástico para evitar a carbonatação dos materiais.
Em seguida a esse período inicial, os CPs utilizados como substratos foram limpos com uma leve escovação manual e chapiscados em uma das faces. Na preparação do chapisco, empregou-se a dosagem 1:3 (em volume), por ser a mais utilizada nas obras da região (MALHEIRO, 2008), e sua aplicação seguiu a aplicação manual com colher de pedreiro, de modo semelhante à prática de obra. Esse procedimento teve o auxílio de uma peneira

44 Malheiro, R. M. de C.; Meira, G. R.; Lima, M. S. de. 
de malha fina, com o objetivo de produzir um chapisco menos espesso e mais uniforme.

Após um repouso de mais 3 dias, aplicou-se a argamassa de revestimento na mesma face, em espessuras de $2,5 \mathrm{~cm}$ e de $4 \mathrm{~cm}$, compondo as tipologias de corpo de prova apresentadas na Figura 3. As camadas de revestimento foram realizadas com argamassas em três dosagens diferentes: 1:3, 1:1:6 e 1:2:9 (cimento:areia e cimento:cal:areia - dosagens expressas em volume). As dosagens e propriedades das argamassas utilizadas são apresentadas na Tabela 2.

As espessuras e dosagens adotadas tiveram como referência uma pesquisa de campo realizada na cidade de João Pessoa, Paraíba, Brasil (MALHEIRO, 2008), que, através de questionários aplicados em obras em fase de acabamento e localizadas numa faixa de aproximadamente $500 \mathrm{~m}$ em relação ao mar, traçou um perfil sobre os revestimentos externos utilizados na região de estudo. No que se refere à espessura de revestimento, esse perfil mostra que $68 \%$ das obras estudadas utilizaram espessuras médias de revestimento entre $3 \mathrm{~cm}$ e $4 \mathrm{~cm}$, enquanto $16 \%$ utilizaram espessuras entre $1 \mathrm{~cm}$ e $2,5 \mathrm{~cm}$, o que contribuiu para a escolha das espessuras de revestimento de $2,5 \mathrm{~cm}$ e de $4 \mathrm{~cm}$ no presente estudo. Cumpre esclarecer que, embora uma espessura de revestimento de $4 \mathrm{~cm}$ não deva ser recomendada, ela foi usualmente observada na pesquisa de campo. Por esse motivo e considerando o estudo da influência da variável espessura de revestimento no presente trabalho, manteve-se seu emprego como espessura analisada.

Para cada situação, foram moldados $3 \mathrm{CPs}$, os quais, após 28 dias da aplicação da argamassa de revestimento (período no qual os CPs também foram protegidos com filme plástico para evitar carbonatação), receberam uma pintura epóxi em cinco de suas faces, deixando apenas uma face livre, para a penetração dos íons cloreto durante os ensaios. Esse procedimento teve como objetivo a simulação de um fluxo unidirecional. As principais etapas de preparação dos CPs estão resumidas na Figura 4.

Figura 3 - Tipologias dos corpos de prova empregados na pesquisa com revestimento de $40 \mathrm{~mm}, 25 \mathrm{~mm}$ e sem revestimento

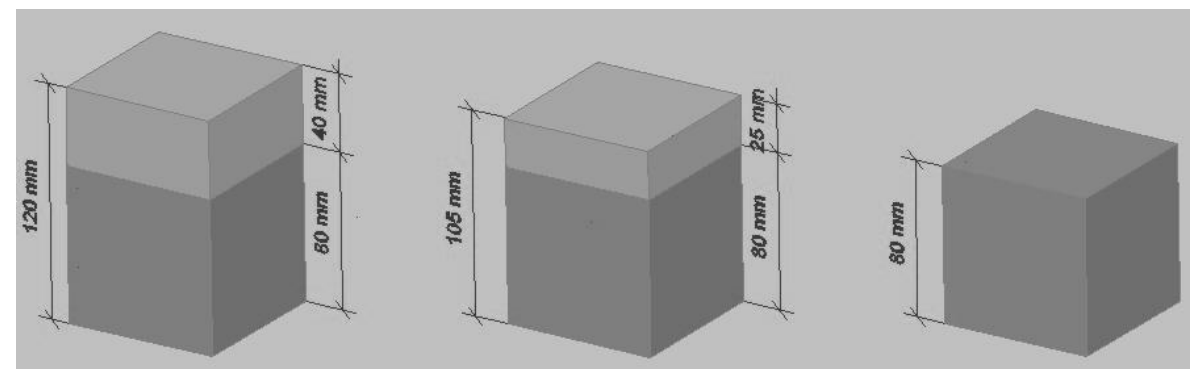

Figura 4 - (a) CPs limpos; (b) Chapisco aplicado; (c) CPs revestido com argamassa; e (d) Pintura epóxi aplicada

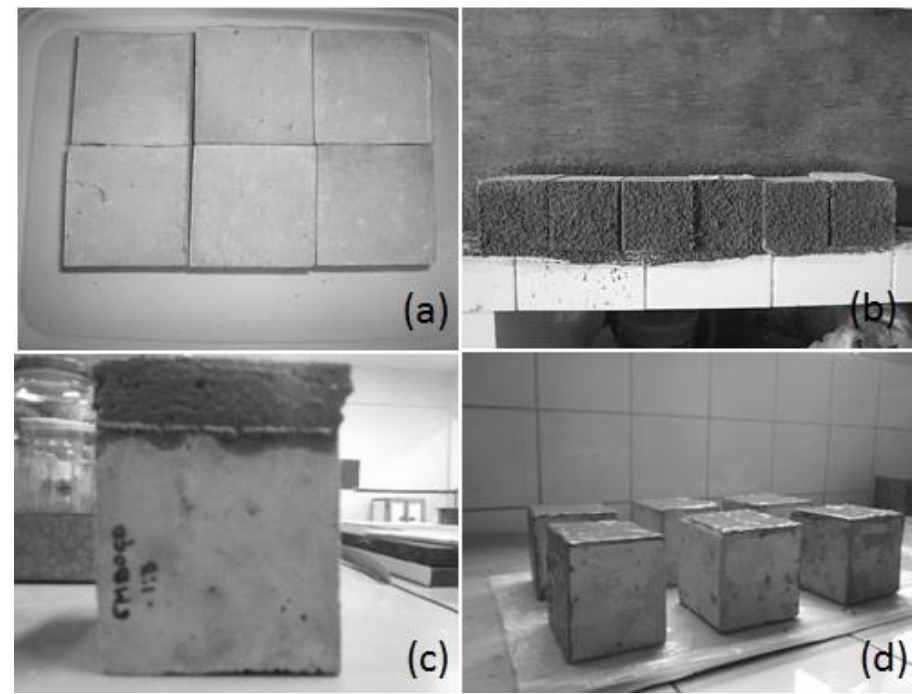




\section{Ensaios acelerados, extração de amostras e análises químicas}

Após as etapas descritas no item "Preparação dos corpos de prova", os CPs foram submetidos a ciclos de imersão e secagem em solução de cloreto de sódio, com concentração de um molar. A imersão se deu durante 3 dias, e a secagem durante 4 dias, em ambiente de laboratório (UR $=68 \pm 5 \%$, $\mathrm{T}=26 \pm 3{ }^{\circ} \mathrm{C}$ ). Esses ciclos se repetiram durante 7 semanas. A escolha desse número de ciclos se deu em função da busca de compatibilizar o tempo de penetração de cloretos no concreto e na argamassa, uma vez que esses materiais possuem características de transporte bastante distintas. Isso ocorreu a partir de ensaios preliminares, realizados com diversos períodos de exposição. Embora os resultados numéricos desses ensaios preliminares não tenham sido possíveis de resgatar, observou-se que períodos de exposição mais curtos poderiam dificultar a avaliação do transporte de cloretos no concreto, devido às baixas concentrações e pouca profundidade de penetração nessa camada. Por outro lado, períodos de observação mais longos poderiam provocar um acúmulo acentuado de cloretos nas argamassas, dificultando a análise comparativa entre as argamassas. Esses aspectos também foram ponderados em função do emprego de duas espessuras de revestimento. Como resultado, optou-se pelo emprego de um único período de exposição para todos os ensaios aqui realizados.

Os corpos de prova de referência (sem argamassa de revestimento) foram submetidos às mesmas condições impostas aos CPs em sistema duplo. Durante a realização desses ensaios, os recipientes empregados permaneceram fechados, de forma a evitar a evaporação de parte da solução e a consequente alteração de sua concentração.

Ao saírem dos ensaios em ciclos de imersão e secagem, os corpos de prova foram marcados de acordo com a profundidade desejada e pulverizados a cada $5 \mathrm{~mm}$ no sentido superfícieinterior. Nas proximidades da interface argamassaconcreto, essa espessura foi reduzida para $2,5 \mathrm{~mm}$, a fim de que se pudessem obter resultados mais detalhados nessa região. A Figura 5 mostra esquematicamente a distribuição de amostras extraídas dos corpos de prova estudados. A extração dessas amostras ocorreu a seco para evitar a remoção de cloretos por lavagem e foi realizada mediante o emprego de um equipamento de corte/desbaste com disco diamantado.

As amostras pulverizadas foram preparadas segundo procedimento descrito pelo RILEM (2002), o qual considera a extração dos cloretos totais em meio ácido, seguido de fervura e posterior filtragem. De modo igual ao caso da água utilizada na preparação dos CPs, os teores de cloretos totais foram determinados a partir da técnica de titulação potenciométrica, seguindo procedimento semelhante ao descrito na ASTM C114 (AMERICAN..., 1992). Esse tipo de titulação foi escolhido, principalmente, por se apresentar adequado para os teores de cloreto observados e por não depender da acuidade visual do operador para determinar o ponto de equivalência (PEREIRA; CINCOTTO, 2001).

\section{Resultados}

Os perfis de cloretos resultantes da fase experimental para sistemas duplos são apresentados nas Figuras 6 e 7. Considerando-se as diferenças na composição dos materiais empregados, optou-se por expressar os resultados em percentuais relativos à massa das amostras. Os valores apresentados representam os valores médios e os desvios padrão relativos a cada profundidade analisada, tanto na Figura 6 quanto na Figura 7.

Figura 5 - Esquema da distribuição dos cortes: (a) Sistema duplo com 4,0 cm de revestimento; (b) Sistema duplo com 2,5 cm de revestimento; e (c) CPs de referência em concreto

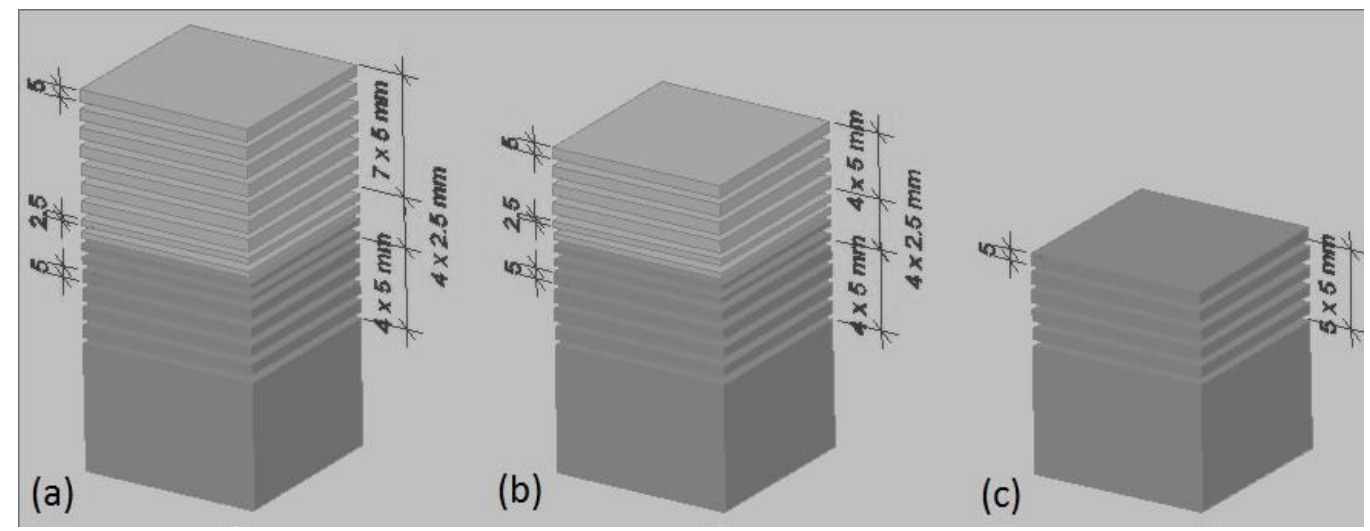

46 Malheiro, R. M. de C.; Meira, G. R.; Lima, M. S. de. 
Nos perfis mostrados na Figura 6, observa-se tendência de crescimento das concentrações de cloretos com o aumento da porosidade da argamassa, bem como a formação de picos tênues na região próxima à superfície das argamassas. Tais picos, quando bem definidos, são típicos do efeito pele (ANDRADE; DIEZ; ALONSO, 1997). Considerando que tal formação corresponde a apenas uma tendência, que não se repete em todos os perfis, e que a forma interna dos perfis se assemelha aos perfis típicos de difusão, é provável que o transporte por difusão tenha prevalecido. Isso se justifica pelo curto espaço de tempo destinado à secagem, associado à elevada umidade relativa observada no ambiente de laboratório (típica da região), resultando em trocas de umidade mais superficiais entre os materiais e o ambiente.

Também se observa um acúmulo de cloretos na região anterior à interface argamassa-concreto. Tal acúmulo é seguido de uma queda significativa na concentração de cloretos no concreto logo após a interface. Esse comportamento evidencia que há resistência à passagem dos cloretos da argamassa para o concreto, o que é consequência das diferenças na capacidade de transporte de massa entre a primeira e o segundo (ANDRADE; DIEZ; ALONSO, 1997).

Comportamento semelhante também é observado na Figura 7. Contudo, dada a maior espessura de revestimento, menores concentrações de cloretos são observadas na camada de concreto. Isso pode ser claramente observado nos CPs em sistemas duplos com argamassas menos porosas. De modo particular, é possível que alguns pontos dos perfis apresentados possam se deslocar em relação à tendência esperada, como, por exemplo, nos CPs com argamassa 1:1:6, após a interface. Isso se explica pelo fato de as concentrações serem expressas em relação à massa da amostra e de o concreto ser um material heterogêneo, variando a quantidade de pasta em cada amostra. Portanto, seções com mais agregado colaboram para teores de cloretos mais baixos, e seções com mais pasta, para teores mais elevados. Contudo, esses deslocamentos são pontuais e não comprometem a análise do conjunto de dados.

Comparando-se as Figuras 6 e 7 com o perfil apresentado na Figura 8, que se refere ao sistema de referência (sem revestimento), pode-se claramente observar concentrações de cloretos no concreto significativamente superiores nesse último caso, com valores nas camadas superficiais que superem em mais de duas vezes aqueles referentes à camada de concreto em sistemas duplos com argamassa 1:3. Isso contribui para evidenciar que a camada de revestimento pode desempenhar um papel complementar de proteção em estruturas de concreto em relação à penetração de cloretos, conforme se discute na seção "Análise e discussão dos resultados", aspecto este não incorporado pela normalização brasileira referente a projeto de estruturas de concreto - NBR 6118 (ABNT, 2007).

Figura 6 - Perfis de cloretos obtidos mediante ensaio de imersão e secagem para os CPs moldados com $2,5 \mathrm{~cm}$ de revestimento de argamassa

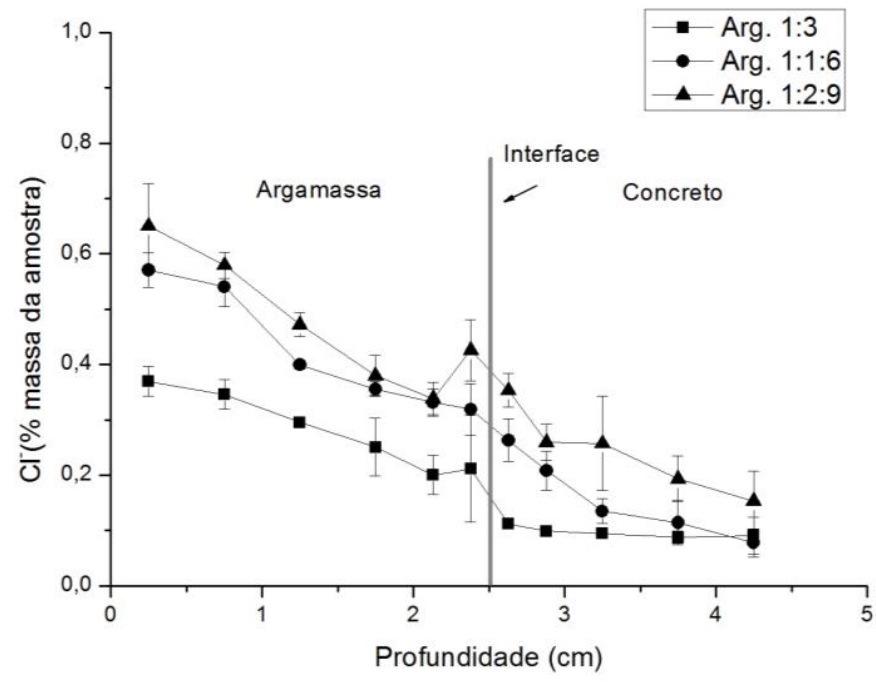


Figura 7 - Perfis de cloretos obtidos por meio de ensaio de imersão e secagem para os CPs moldados com $4,0 \mathrm{~cm}$ de revestimento de argamassa

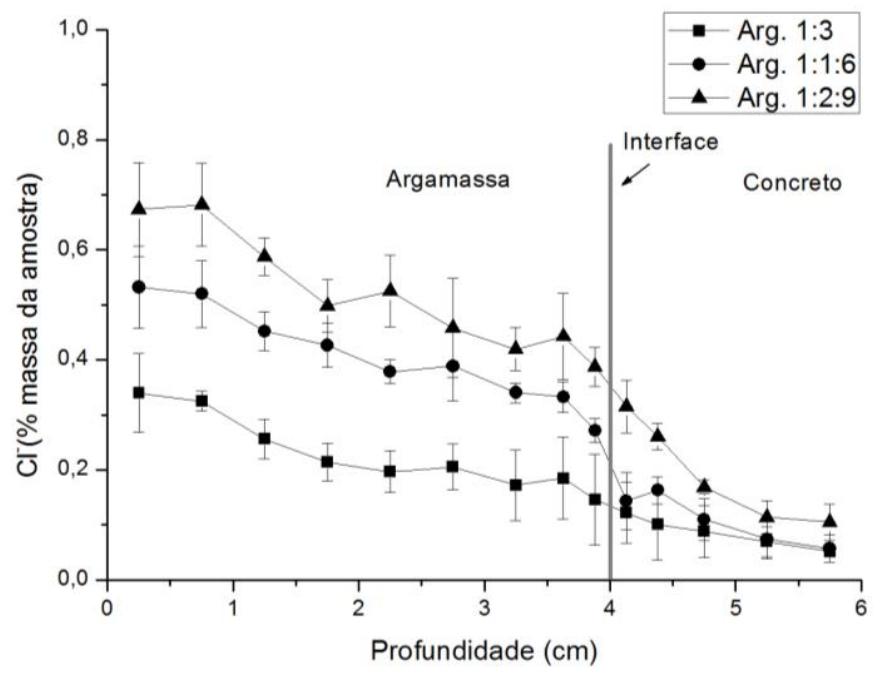

Figura 8 - Perfil de cloretos obtido por meio do ensaio de imersão e secagem para os CPs de referência moldados em concreto

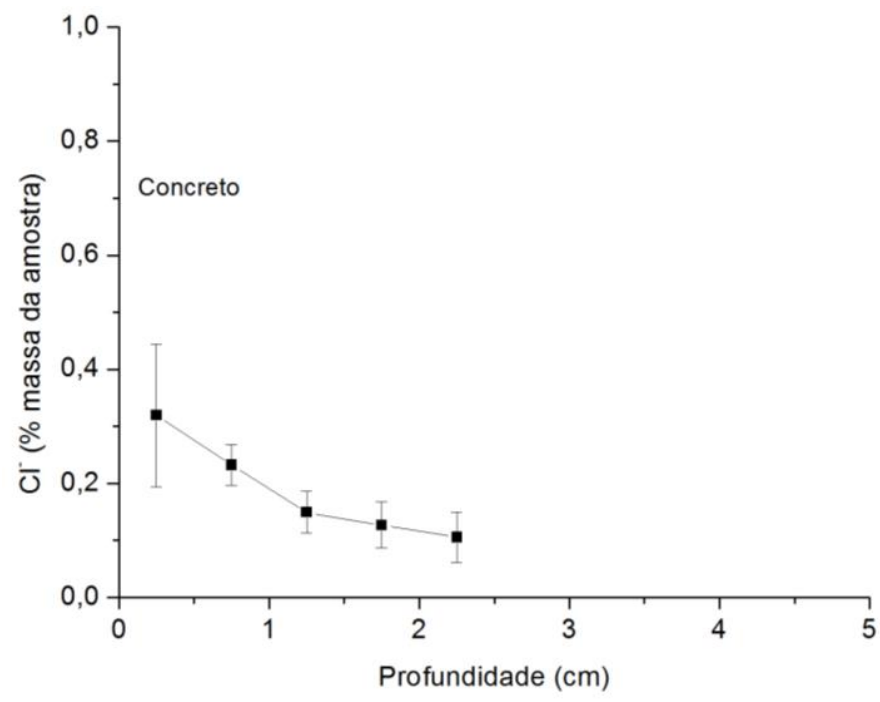

\section{Análise e discussão dos resultados}

Nesta seção, são discutidas as influências das características dos materiais, da espessura da camada de revestimento e do efeito resistência na interface entre argamassa e concreto nos perfis de cloretos obtidos. Cabe ressaltar que essas análises foram pautadas em ensaios de curta duração em ambiente de laboratório, onde, apesar da adoção das etapas executivas observadas na região do estudo, tem-se melhor controle das atividades experimentais. Nesse sentido, não foram considerados, neste trabalho, aspectos como a qualidade executiva da camada de revestimento praticada nas obras, bem como a degradação dessa camada ao longo do tempo, aspectos estes que também podem ter reflexo no desempenho do revestimento em relação ao papel complementar de proteção da estrutura. A influência da cal no transporte de cloretos foi analisada de forma indireta, através das alterações na microestrutura das argamassas, com o incremento do teor de cal em substituição ao cimento. Nesse sentido, os resultados e análises aqui apresentados devem ser vistos no âmbito dessas limitações. 


\section{Influência das características dos materiais}

Os perfis de cloretos apresentados nas Figuras de 6 e 7 mostram que as argamassas estudadas se comportam de forma diferenciada com relação à penetração de cloretos. Observa-se que, quanto mais rica em cimento e menos porosa é a argamassa (Tabela 2), menor é a concentração de cloretos verificada na região do revestimento. Essa relação está intimamente ligada à redução de porosidade das argamassas mais ricas e a sua maior quantidade de $\mathrm{C}_{3} \mathrm{~A}$ (BYFORS, 1990; RASHEEDUZZAFAR; HUSSAIN; ALSAADOUN, 1990), decorrente do maior consumo de cimento.

Com relação à redução da porosidade nas argamassas mais ricas, os resultados de caracterização apontam um decréscimo de porosidade da argamassa 1:2:9 para a argamassa $1: 3$, que pode ser visualizado pela redução dos índices de vazios de $23,7 \%$ para $18,2 \%$ (Tabela 2). Esse fato se reflete nos perfis de cloretos apresentados nas Figuras 6 e 7, uma vez que a porosidade mais aberta facilita o transporte de cloretos (TUUTTI, 1982; JAGERMANN, 1990). No que se refere ao teor de $\mathrm{C}_{3} \mathrm{~A}$, o maior consumo de cimento significa maior quantidade de $\mathrm{C}_{3} \mathrm{~A}$ disponível para colaborar na fixação dos íons cloreto na matriz (BYFORS, 1990; RASHEEDUZZAFAR; HUSSAIN; ALSAADOUN, 1990). Essa maior capacidade de fixação reduz a quantidade de cloretos livres, que são os que efetivamente participam do transporte. Dessa forma, são observados perfis com menor avanço das concentrações de cloretos.

As diferenças de transporte de cloretos na argamassa influenciam no transporte desses íons no concreto. As Figuras 6 e 7 mostram que existe uma sintonia entre os perfis de cloretos na camada de revestimento e aqueles na camada de concreto, ou seja, se chegam menos cloretos na interface entre os materiais, menos serão transportados para o interior do concreto. A análise das Figuras 6 e 7 mostra o efeito positivo da argamassa de revestimento na redução do teor de cloretos no interior do concreto. No entanto, essa proteção depende de características da argamassa, como sua porosidade e sua capacidade de fixação de cloretos.

Outra maneira de visualisar a influência da dosagem das argamassas sobre os perfis de cloretos no concreto é através da relação entre a concentração total acumulada na camada de argamassa, correspondente ao total de cloretos acumulados nessa região (área sob o perfil na camada de argamassa), e a concentração total acumulada no concreto (área sob o perfil na camada de concreto), o que pode ser visualizado na Figura 9. A figura mostra que há uma relação de crescimento não linear que tende a uma maior transferência de cloretos da argamassa para o concreto à medida que se acumulam mais cloretos na zona da argamassa.

Esse comportamento se explica pelo fato de as argamassas mais porosas contribuírem para um rápido transporte inicial em sua zona e, por conseguinte, aumentarem a concentração superficial no concreto, o que favorece o aumento do transporte na zona do concreto. A Tabela 3 esclarece esse aspecto quando apresenta os resultados da concentração superficial de cloretos no concreto (Cs) e o total de cloretos acumulado nessa região. Esses resultados foram obtidos a partir das regressões apresentadas na seção "Efeito da espessura da camada de revstimento", que indicam, na profundidade zero, os valores de Cs, e da área sob os perfis apresentados nas Figuras 6, 7 e 8, na fração concreto, que representa o total de cloretos acumulado na camada de concreto.

\section{Figura 9 - Relação entre o acúmulo de cloretos na argamassa e no concreto}

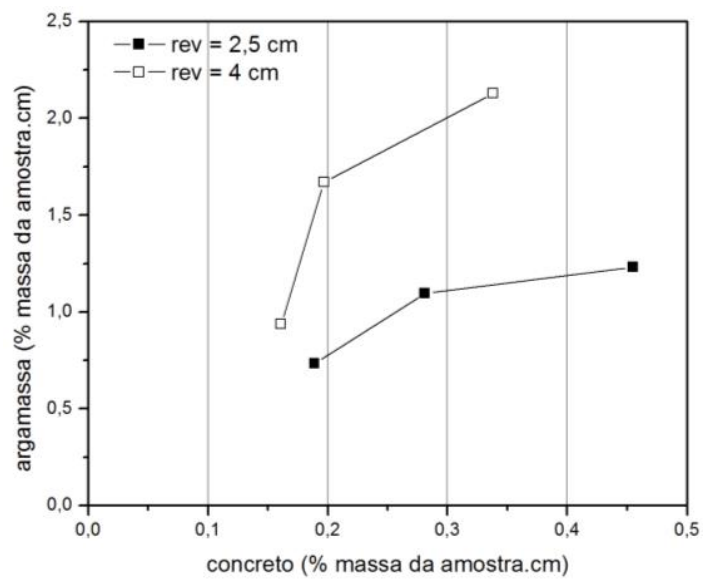


Tabela 3 - Relação entre Cs e o acúmulo de cloretos no concreto

\begin{tabular}{|c|c|c|c|}
\hline \multicolumn{2}{|c|}{ Tipologia dos corpos de prova } & \multirow[b]{2}{*}{$\begin{array}{c}\text { Cs concreto } \\
(\% \text { massa da amostra) }\end{array}$} & \multirow{2}{*}{$\begin{array}{c}\text { Área sob o perfil na fração } \\
\text { concreto } \\
\text { (\% massa da amostra.cm) }\end{array}$} \\
\hline $\begin{array}{c}\text { Espessura do } \\
\text { revestimento }(\mathrm{cm})\end{array}$ & Argamassa & & \\
\hline 0 & --- & 0,38 & 0,47 \\
\hline \multirow[t]{3}{*}{2,5} & $1: 2: 9$ & 0,34 & 0,45 \\
\hline & $1: 1: 6$ & 0,27 & 0,28 \\
\hline & $1: 3$ & 0,12 & 0,19 \\
\hline \multirow[t]{3}{*}{4} & $1: 2: 9$ & 0,31 & 0,34 \\
\hline & $1: 1: 6$ & 0,19 & 0,20 \\
\hline & $1: 3$ & 0,15 & 0,16 \\
\hline
\end{tabular}

\section{Efeito da espessura da camada de revestimento}

Para avaliar a influência da espessura da camada de revestimento em argamassa no transporte de cloretos no interior do concreto, foram feitos ajustes baseados na solução da $2^{\mathrm{a}}$ Lei de Fick. Para tal, os perfis na camada de concreto foram reescalonados, segundo procedimento descrito por Andrade, Diez e Alonso (1997), conforme mostra a Figura 10. Cumpre lembrar que, neste caso, aceitou-se a prevalência do transporte por difusão na camada de concreto, conforme discutido na seção "Resultados".

Os resultados são apresentados na Figura 11 e indicam que a espessura do revestimento é um fator que influencia o transporte de cloretos no interior do concreto. Contudo, essa influência ocorre de maneira mais clara para as argamassas menos porosas, indicando que esse efeito benéfico só deve ser considerado a partir de determinado nível de porosidade das argamassas; no caso específico deste estudo, para as argamassas 1:3 e $1: 1: 6$.

Considerando o teor crítico de cloretos, que neste caso corresponde a $0,065 \%$ da massa do concreto $(0,4 \%$ da massa do cimento segundo Glass e Buenfeld (1997)), a Tabela 4 mostra a redução da profundidade em que esse teor é atingido na camada do concreto, à medida que se aumenta a espessura do revestimento.

Comparando-se os resultados apresentados na Tabela 4 e as curvas apresentadas na Figura 11, pode-se dizer que 2,5 cm de argamassa 1:1:6 equivalem, em média, a $0,80 \mathrm{~cm}$ de concreto, enquanto para a argamassa 1:3 essa relação de equivalência é de $0,60 \mathrm{~cm}$. Essa menor relação de equivalência para a argamassa 1:3 é, na verdade, uma consequência do processo de ajuste, que gerou um tramo final mais elevado, para um perfil originalmente já com baixos teores de cloretos. No caso de $4 \mathrm{~cm}$ de espessura de revestimento, essa equivalência corresponde a $1,10 \mathrm{~cm}$ e $1,25 \mathrm{~cm}$ respectivamente. $\mathrm{O}$ revestimento 1:2:9 teve pouca capacidade de proteção, com perfis mais próximos para as espessuras de revestimento de $0 \mathrm{~cm}$ e 2,5 $\mathrm{cm}$, e espessura equivalente de apenas $0,55 \mathrm{~cm}$ para o revestimento de $4 \mathrm{~cm}$ de espessura.

\section{Efeito resistência na interface entre argamassa e concreto}

Os perfis de cloretos referentes aos corpos de prova em sistema duplo (argamassa e concreto), apresentados nas Figuras 6 e 7, apontam a existência de um acúmulo de cloretos na região imediatamente anterior à interface, seguido de uma redução no teor de cloretos na região do concreto. Essa redução no teor de cloretos, quando se passa do material argamassa para o material concreto, é vista como um efeito benéfico de resistência à penetração dos íons cloreto imposto pelas características dos materiais.

Esse efeito está associado a diferenças na capacidade de transporte dos materiais (ANDRADE; ALONSO, 1997). Nesse sentido, a diferença de porosidade que existe entre a argamassa de revestimento e o concreto é um fator que contribui para esse acúmulo de íons na interface. Assim, espera-se que, quanto menor a porosidade da argamassa, ou seja, quanto mais próxima a porosidade da argamassa for da porosidade do concreto, menor será o efeito resistência.

Ajustando-se as equações representativas do transporte de cloretos na argamassa e no concreto aos perfis obtidos (Equações 1 a 3), é possível obterem-se as curvas apresentadas na Figura 12. De acordo com essa figura e a Tabela 5, o valor de $\mathrm{R}$, representativo do efeito resistência e correspondente à relação entre a concentração na interface no lado argamassa e no lado concreto, apresenta leve diminuição em função do aumento da porosidade da argamassa para a espessura de revestimento de $2,5 \mathrm{~cm}$, fato que, em princípio, vai de encontro às expectativas iniciais. 
Figura 10 - Reescalonamento empregado para os perfis de cloretos no concreto

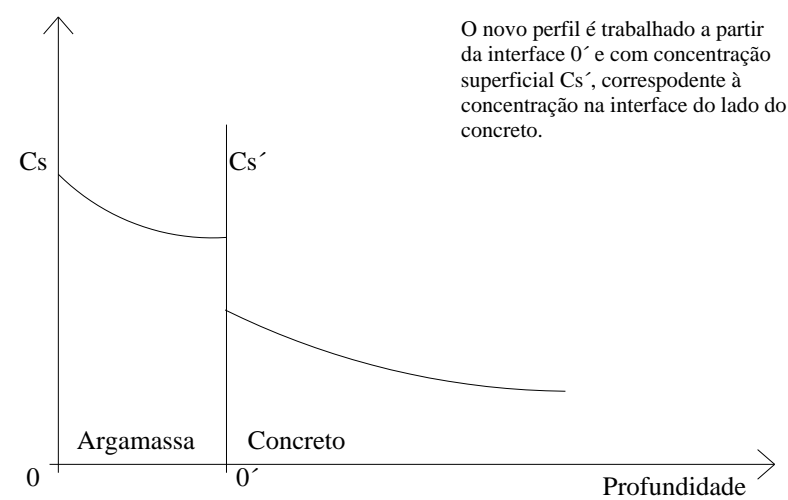

Figura 11 - Perfis de cloretos ajustados na zona do concreto, para as argamassas (a) 1:3, (b) 1:1:6 e (c) 1:2:9
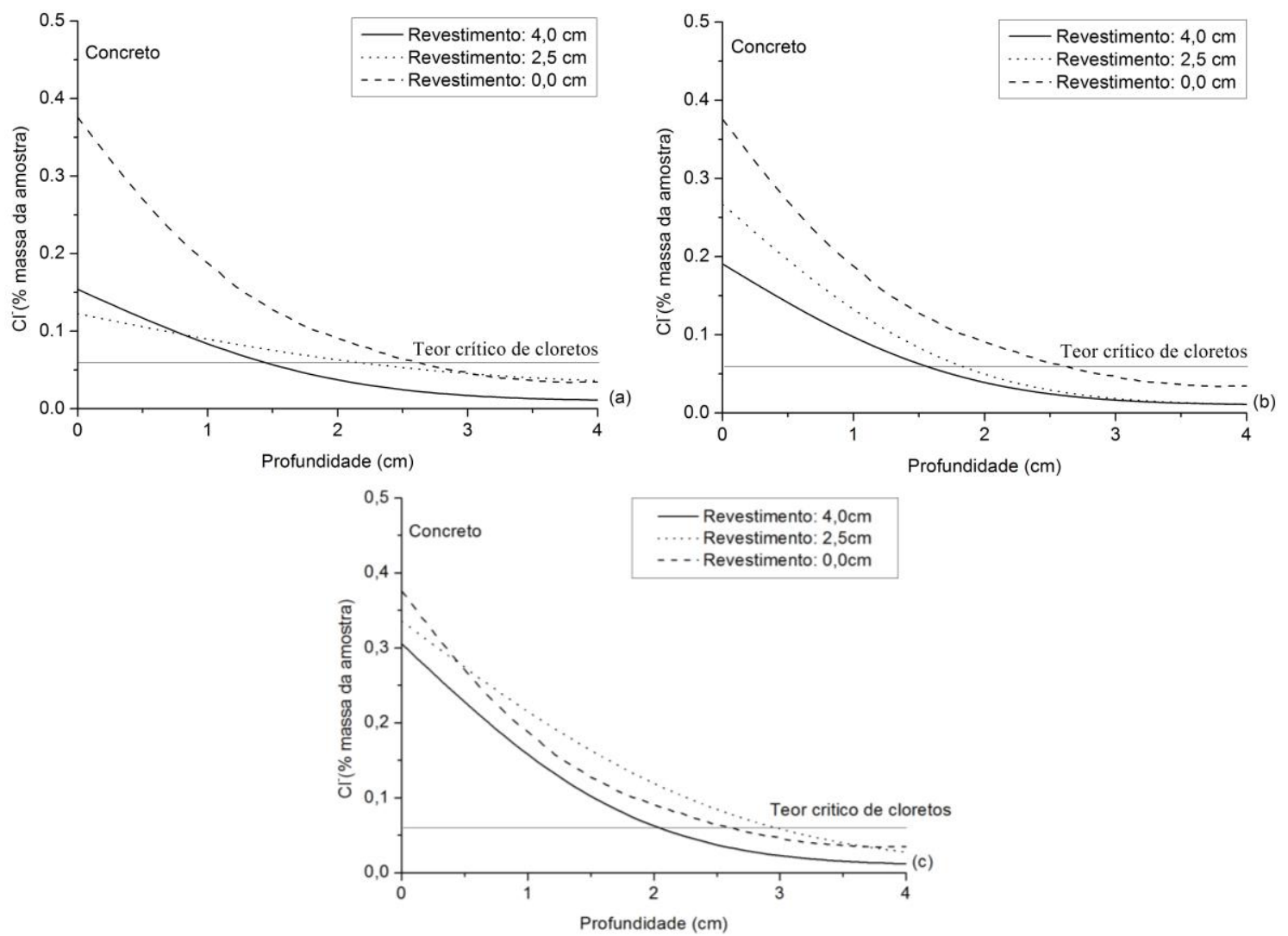

Tabela 4 - Relação entre espessura de revestimento e profundidade do teor crítico de cloretos

\begin{tabular}{ccc}
\hline $\begin{array}{c}\text { Tipologia dos corpos de prova } \\
\text { Espessura do } \\
\text { revestimento (cm) }\end{array}$ & Argamassa & $\begin{array}{c}\text { Profundidade do teor } \\
\text { crítico de cloretos (cm) }\end{array}$ \\
\hline 0,0 & --- & 2,65 \\
\hline 2,5 & $1: 2: 9$ & 2,90 \\
& $1: 1: 6$ & 1,85 \\
& $1: 3$ & 2,05 \\
\hline 4 & $1: 2: 9$ & 2,10 \\
& $1: 1: 6$ & 1,55 \\
& $1: 3$ & 1,4 \\
\hline
\end{tabular}


Figura 12 - Perfis ajustados para as espessuras de revestimento de (a) $2,5 \mathrm{~cm}$ e (b) $4,0 \mathrm{~cm}$
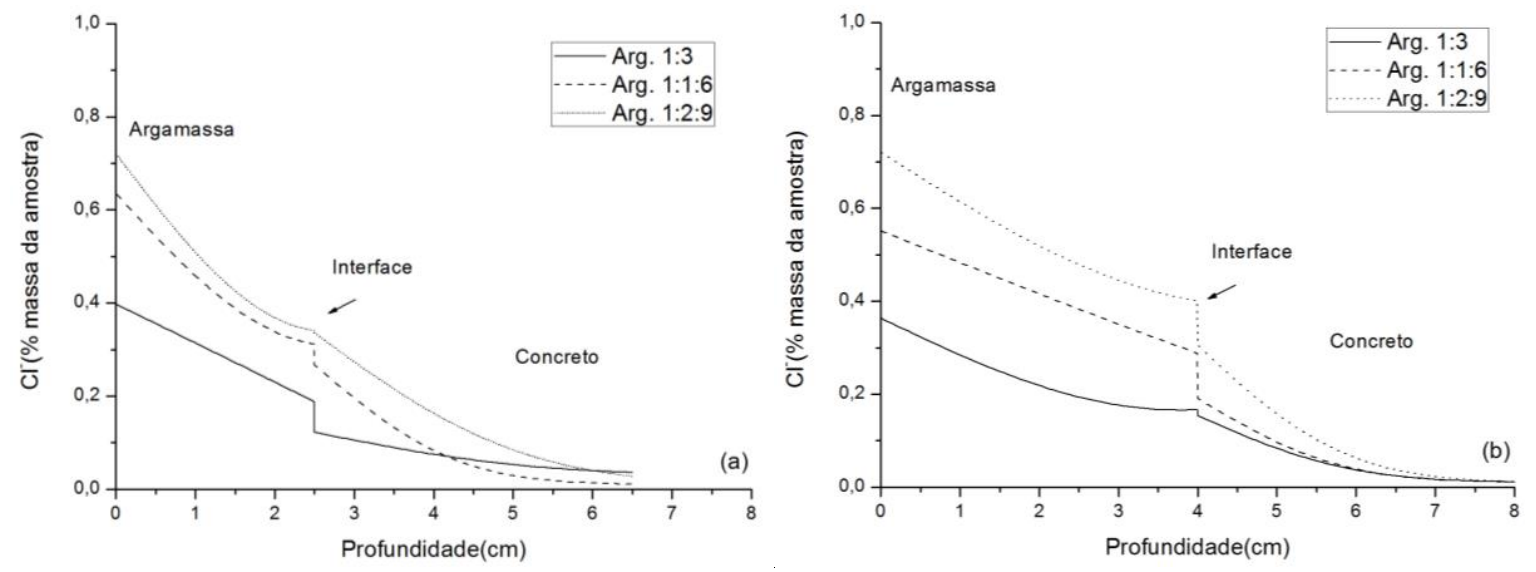

Tabela 5 - Efeito resistência na interface argamassa-concreto, medido através do parâmetro $\mathbf{R}$

\begin{tabular}{ccc}
\hline \multicolumn{2}{c}{ Tipologia dos corpos de prova } & \\
\cline { 1 - 2 } $\begin{array}{c}\text { Espessura do } \\
\text { revestimento }(\mathbf{c m})\end{array}$ & Argamassa & \\
\hline 2,5 & $1: 2: 9$ & \\
& $1: 1: 6$ & 1,01 \\
& $1: 3$ & 1,17 \\
& $1: 2: 9$ & 1,53 \\
\hline 4 & $1: 1: 6$ & 1,41 \\
& $1: 3$ & 1,50 \\
& & 1,08 \\
\hline
\end{tabular}

Investigando mais detalhadamente esse comportamento em relação à espessura de revestimento de $2,5 \mathrm{~cm}$, pode-se observar que os perfis referentes às argamassas de elevada porosidade, mostrados nas Figuras 6 e 12(a), apresentam um acúmulo de cloretos na região imediatamente anterior à região de interface em trecho mais extenso, representada por uma horizontalidade maior dos perfis nessa região. Esse acúmulo é oriundo da chegada precoce dos íons cloreto na região. Quanto maior é a região de acúmulo anterior à interface, maior é o período em que os cloretos provenientes da região da argamassa estiveram sendo acumulados nessa região e, por conseguinte, estiveram sendo transferidos para a região do concreto. Esse aumento no período de transferência possibilita a redução na diferença de concentrações entre argamassa e concreto na interface e, consequentemente, proporciona a diminuição do valor de $\mathrm{R}$.

Para a espessura de revestimento de $4 \mathrm{~cm}$, esse acúmulo não é tão visível, o que indica que o efeito do acúmulo precoce na região imediatamente anterior à interface, provavelmente, não foi tão significativo, e este comportamento se traduz nos valores de R. Observou-se apenas uma leve inversão nos valores de $\mathrm{R}$ para as argamassas
1:2:9 e 1:1:6, indicando que esse efeito ainda estava em fase inicial.

Em virtude desse fato, não se deve comparar de forma direta os valores de $\mathrm{R}$, pois se estaria comparando diferentes situações de transporte, já que, para as porosidades mais elevadas e CPs com espessura de revestimento de $2,5 \mathrm{~cm}$, o transporte de cloretos da argamassa para o concreto estaria ocorrendo em patamares mais elevados e há mais tempo do que para as argamassas de menor porosidade. Dessa forma, o valor de $\mathrm{R}$ não é constante, mas deve sofrer diminuição em função do tempo de ensaio ou observação. Os valores aqui observados representam, portanto, aqueles relativos ao final dos ensaios.

\section{Conclusões}

Os experimentos realizados indicam que as argamassas de revestimento atuam de forma positiva em relação ao retardamento da penetração de cloretos no interior do concreto revestido. No entanto, esse comportamento depende das características dos materiais. No que se refere às características das argamassas, aquelas com maior consumo de cimento e menos porosas têm participação mais expressiva no efeito retardador em relação à penetração de cloretos no concreto. 
Argamassas muito pobres devem ter seu efeito de proteção desconsiderado, dada sua mínima contribuição.

Além disso, observa-se a existência de um efeito resistência no transporte de cloretos da argamassa para o concreto. Esse efeito é comum a todas as argamassas estudadas e decorre das diferenças na capacidade de transporte de massa de cada um dos materiais estudados. Contudo, no âmbito do efeito resistência, a análise do parâmetro $\mathrm{R}$ (relativo ao efeito resistência) deve ser feita com cautela, levando-se em conta o acúmulo precoce de cloretos, que ocorre antes da interface argamassaconcreto para tempos de ensaio maiores.

Essas afirmações tomadas em conjunto mostram que, embora as argamassas apresentem porosidade superior à do concreto, podem representar uma proteção adicional em relação ao retardamento na penetração de cloretos no concreto. Esse efeito pode ser trabalhado na forma de espessura equivalente de concreto e se situou na faixa entre 0,6 e $1,25 \mathrm{~cm}$ para as condições de estudo deste trabalho.

Por fim, cabe ressaltar que as análises aqui realizadas foram pautadas em ensaios laboratoriais de curta duração e que aspectos como a qualidade executiva da camada de revestimento praticada nas obras, bem como a degradação dessa camada ao longo do tempo, que certamente têm reflexo no desempenho do revestimento em relação a esse papel complementar de proteção da estrutura, não foram aqui considerados.

\section{Referências}

AITCIN, P. C. Concreto de Alto Desempenho. São Paulo: Pini, 2000. 667 p.

AL-KHAJA, A. W. Influence of Temperature, Cement Type and Level of Concrete Consolidation on Chloride Ingress in Conventional and HighStrength Concretes. Construction and Building Materials, v. 11, p. 9-13, 1997.

AMERICAN SOCIETY FOR TESTING AND

MATERIALS. ASTM C-114: standard test methods for chemical analysis of hydraulic cement. Philadelphia, 1992.

ANDRADE, C.; ALONSO, C. Modeling of Skin Effects on Diffusion Process in Concrete. In: INTERNATIONAL RILEM WORKSHOP ON CHLORIDE PENETRATION INTO CONCRETE, Paris, 1995. Proceedings... Paris: RILEM, 1997. p. 182-194.
ANDRADE, C.; DIEZ, J. M.; ALONSO, C. Modeling of Skin Effects on Diffusion Process in Concrete. Advanced Cement Based Materials, v. 6, p. 39-44, 1997.

\section{ASSOCIAÇÃO BRASILEIRA DE NORMAS}

TÉCNICAS. NBR 7215: cimento Portland:

determinação da resistência à compressão. Rio de Janeiro, 1996.

ASSOCIAÇÃO BRASILEIRA DE NORMAS TÉCNICAS. NBR NM 76: cimento Portland: determinação da finura pelo método de permeabilidade ao ar (Método de Blaine). Rio de Janeiro, 1998.

ASSOCIAÇÃO BRASILEIRA DE NORMAS TÉCNICAS. NBR NM 23: cimento Portland e outros materiais em pó: determinação da massa específica. Rio de Janeiro, 2001.

ASSOCIAÇÃO BRASILEIRA DE NORMAS TÉCNICAS. NBR NM 15: cimento Portland: análise química: determinação de resíduo insolúvel. Rio de Janeiro, 2004a.

ASSOCIAÇÃO BRASILEIRA DE NORMAS TÉCNICAS. NBR NM 18: cimento Portland: análise química: determinação de perda ao fogo. Rio de Janeiro, 2004b.

ASSOCIAÇÃO BRASILEIRA DE NORMAS TÉCNICAS. NBR 6118: projeto de estruturas de concreto: procedimento. Rio de Janeiro, 2007.

ASSOCIAÇÃO BRASILEIRA DE NORMAS TÉCNICAS. NBR 7211: agregados para concreto: especificação. Rio de Janeiro, 2005.

BAKKER, R. F. M. Initiation Period. In: SCHIESSL, P. (Ed.). Corrosion of Steel in Concrete. New York: RILEM; Chapman and Hall, 1988. p. 22-55.

BYFORS, K. Chloride: initiated reinforcement corrosion: chloride binding. Stockholm: CBI, 1990. 121 p. Report 1:90.

CASTRO, P., RINCÓN, O. T., PAZINI, E. J. Interpretation of Chloride Profiles from Concrete Exposed to Tropical Marine Environments.

Cement and Concrete Research, v. 31, n. 4, p. 529-537, abr. 2001.

CRANK, J. The Mathematics of Diffusion. $2^{\text {nd }}$. ed. Oxford: Oxford University Press, 1975.

GLASS, G. K.; BUENFELD, N. R. Chloride Threshold Levels for Corrosion Induced Deterioration of Steel in Concrete. In: INTERNATIONAL RILEM WORKSHOP ON CHLORIDE PENETRATION INTO CONCRETE, Paris, 1995. Proceedings... Paris: RILEM, 1997. p. 429-440. 
GUIMARÃES, A. T. C.; HELENE, P. R. L. Chloride Diffusion and the Influence of the Saturation Degree of the Concrete. In: RILEM WORKSHOP ON TESTING AND MODELING THE CHLORIDE INGRESS INTO CONCRETE, 3., Madri, 2005. Proceedings... Paris: RILEM, 2005. p. 237-256.

JAEGERMANN, C. Effect of Water-Cement Ratio and Curing on Chloride Penetration Into Concrete Exposed to Mediterranean Sea Climate. ACI Materials Journal, v. 87, n. 4, p. 333-339, 1990.

JONES, M. R.; MCCARTHY, M. J.; DHIR, R. K. Chloride Ingress and Reinforcement Corrosion in Carbonated and Sulphated Concrete. In: INTERNATIONAL CONFERENCE ON CORROSION AND CORROSION PROTECTION OF STEEL IN CONCRETE, Sheffield, 1994. Proceedings... Sheffield: Sheffield Academic Press, 1994. p. 365-376.

KREIJGER P C. The Skin of Concrete: Composition and Properties. Matériaux and Constructions, v. 17, n. 100, p. 275-283, 1984.

KRÖPP, J. et al. Transport Mechanisms and Definitions. In: KRÖPP, J.; HILSDORF, H. K. (Eds.). Performance Criteria for Concrete Durability. London: E \& FN Spon, 1995, p. 4-14. Report 12.

LINDVALL, A. Chloride Ingress Data from Field and Laboratory Exposure: influence of salinity and temperature. Cement and Concrete Composites, v. 29, n. 2, p. 88-93, 2007.

MALHEIRO, R. L. M. C. Influência do Revestimento de Argamassa no Transporte de Cloretos em Estruturas de Concreto Armado Inseridas no Meio Urbano. João Pessoa, 2008. 143 p. Dissertação (Mestrado em Engenharia Urbana e Ambiental) - Escola de Engenharia, Universidade Federal da Paraíba, João Pessoa, 2008.

MANGAT, P. S.; GURUSAMY, K. Chloride Diffusion in Steel Fiber Reinforced Marine Concrete. Cement and Concrete Research, v. 17, p. 385-396, 1987.

MANGAT, P. S.; MOLLOY, B. T. Prediction of Long Term Chloride Concentration in Concrete. Materials and Structures, v. 27, p. 338-346, 1994.

MARTÍN-PÉREZ, B. Service Life Modelling of R. C. Highway Structures Exposed to Chlorides. Toronto, 1999. PhD thesis. University of Toronto, Toronto, 1999.
MEIJERS, S. J. H. Computational Modeling of Chloride Ingress in Concrete. The Netherlands, 2003. PhD Thesis. DUP Science, The Netherlands, 2003.

MEIRA, G. et al. Chloride Penetration Into Concrete Structures in Marine Atmosphere Zone: influence of environmental characteristics. In: INTERNATIONAL RILEM WORKSHOP ON INTEGRAL SERVICE LIFE MODELING OF CONCRETE STRUCTURES, Guimarães, 2007. Proceedings... Guimarães: RILEM, 2007a. p. 4754.

MEIRA, G. R. et al. Chloride Penetration Into Concrete Structures in the Marine Atmosphere Zone: relationship between deposition of chlorides on the wet candle and chlorides accumulated into concrete. Cement and Concrete Composites, v. 29, p. 667-676, $2007 \mathrm{~b}$.

NIELSEN, E. P.; GEIKER, M. R. Chloride Diffusion in Partially Saturated Cementitious Material. Cement and Concrete Research, v. 33, p. 133-138, 2003.

NILSSON, L. O.; TANG, L. Transport Mechanisms in Porous Materials: an introduction to their basic laws and correlations. In: INTERNATIONAL CONGRESS ON MODELING OF MICROSTRUCTURE AND ITS POTENTIAL FOR STUDYING TRANSPORT PROPERTIES AND DURABILITY, Saint-Rémylés-Chevreuse, 1996. Proceedings... Saint-Rémylés-Chevreuse: Kluwer Academic Press, 1996. p. 289-311.

PAGE, C. L.; SHORT, N. R.; EL TARRAS, A. Diffusion of Chloride Ions in Hardened Cement Pastes. Cement and Concrete Research, v. 11, n. 3, p. 395-406, 1981.

PEREIRA, L. F. L.; CINCOTO, M. A. Determinação de Cloretos em Concreto de Cimentos Portland: influência do tipo de cimento. São Paulo: USP, 2001. Boletim Técnico da Universidade de São Paulo.

RASHEEDUZZAFAR; HUSSAIN, S. E.; ALSAADOUN, S. S. Effect of Tricalcium Aluminate Content of Cement on Corrosion of Reinforcing Steel in Concrete. Cement and Concrete Research, v. 20, p. 723-738, 1990.

RILEM INTERNATIONAL UNION OF TESTING AND RESEARCH LABORATORIES FOR MATERIALS AND STRUCTURES. RILEM TC 178-TMC: analysis of total chloride content in concrete. Materials and Structures, v. 35, p. 583-585, 2002.

TUUTTI, K. Corrosion of Steel in Concrete. Sweden: CBI, 1982. 468 p. 


\section{Agradecimentos}

À equipe do Laboratório de Ensaios de Materiais e Estruturas da Universidade Federal da Paraíba (Labeme/UFPB) e ao Instituto Federal de Educação, Ciência e Tecnologia da Paraíba (IFPB), pelo auxílio no desenvolvimento das atividades gerais do projeto de pesquisa Agradecemos também ao Conselho Nacional de Desenvolvimento Científico e Tecnológico $(\mathrm{CNPq})$ e à Coordenação de Aperfeiçoamento de Pessoal de Nível Superior (Capes), pela concessão de bolsas de estudos.

\section{Raphaele Meireles de Castro Malheiro}

Departamento de Engenharia Civil

Universidade do Minho | Campus de Azurém | Guimarães - Portugal | CEP 4800-058 | Tel.: +(351) 253 257-300 |

E-mail: raphamalheiro@gmail.com

\section{Gibson Rocha Meira}

Departamento de Construção Civil | Instituto Federal de Educação, Ciência e Tecnologia da Paraíba | Av. $1^{\circ}$ de maio, 720, Jaguaribe | João Pessoa - PB - Brasil | CEP 58015-430 | Tel.: (83) 3612-1282 | E-mail: gibsonmeira@yahoo.com

\section{Munique Silva de Lima}

Departamento de Construção Civil | Instituto Federal de Educação, Ciência e Tecnologia da Paraíba | Av. $1^{\circ}$ de maio, 720 , Jaguaribe | João Pessoa - PB - Brasil | CEP 58015-430 | E-mail: munique10@gmail.com

Revista Ambiente Construído

Associação Nacional de Tecnologia do Ambiente Construído

Av. Osvaldo Aranha, $99-3^{\circ}$ andar, Centro

Porto Alegre - RS - Brasil

CEP $90035-190$

Telefone: +55 (51) 3308-4084

Fax: +55 (51) 3308-4054

www.seer.ufrgs.br/ambienteconstruido

E-mail: ambienteconstruido@ufrgs.br 